\title{
长江中游城市群生态系统健康时空演变特征分析
}

\author{
陈万旭 ${ }^{1,2,3}$, 赵雪莲 ${ }^{1,2}$ * $^{\text {, 钟明星 }}{ }^{4}$, 李江风 ${ }^{5}$, 曾 杰 $^{1,2}$ \\ 1 中国地质大学(武汉) 地理与信息工程学院,武汉 430078 \\ 2 中国地质大学(武汉)空间规划与人地系统模拟研究中心,武汉 437008 \\ 3 北京师范大学地表过程与资源生态国家重点实验室,北京 100875 \\ 4 信阳师范学院旅游学院, 信阳 464000 \\ 5 中国地质大学 (武汉) 公共管理学院,武汉 430074
}

\begin{abstract}
摘要: 城市群地区生态系统健康状况关乎城市群的可持续发展,科学测度城市群地区生态系统健康水平对城市群地区生态系统 健康宏观调控政策制定具有重要的实践意义,然而当前生态系统健康评价仍存在不足之处。生态系统服务是反映生态系统健 康状况的重要组成部分,如何把生态系统服务纳人生态系统健康评估框架中,成为了当前研究讨论的热点话题。拟把基于 InVEST 模型评估的生态系统服务纳人生态系统健康评估框架中,构建了基于 “生态系统活力-生态系统组织力-生态系统弹性 -生态系统服务” 的评估框架,结合多源数据对 1995-2015 年长江中游城市群生态系统健康水平时空特征进行测度。结果显 示: (1) 研究期间长江中游城市群地区生态系统健康状况总体有所恶化, 恶化区域主要分布在城市群的核心地区; (2) 研究期间 长江中游城市群地区生态系统健康存在显著的空间依赖性,生态系统健康高值区主要分布在周边山区以及中部的罗霄山脉,生 态系统健康低值区主要分布在平原地区、大城市周边地区以及主要的交通线路沿线地区。本研究结果可以为其他地区生态系 统健康评估以及长江中游城市群地区生态系统健康保护政策制定提供科学借鉴。
\end{abstract}

关键词:生态系统健康; 生态系统服务;InVEST 模型; 时空特征; 长江中游城市群

\section{Spatiotemporal evolution patterns of ecosystem health in the Middle Reaches of the Yangtze River Urban Agglomerations}

\author{
CHEN Wanxu ${ }^{1,2,3}$,ZHAO Xuelian ${ }^{1,2, *}$, ZHONG Mingxing ${ }^{4}$, LI Jiangfeng $^{5}$, ZENG Jie $^{1,2}$ \\ 1 School of Geography and Information Engineering, China University of Geosciences (WUHAN), Wuhan 430078, China \\ 2 Research Center for Spatial Planning and Human-Environmental System Simulation, China University of Geosciences (WUHAN), Wuhan 437008, China \\ 3 State Key Laboratory of Earth Surface Processes and Resource Ecology, Beijing Normal University, Beijing 100875, China \\ 4 Tourism College, Xinyang Normal University, Xinyang 464000, China \\ 5 School of Public Administration, China University of Geosciences (WUHAN), Wuhan 430074, China
}

\begin{abstract}
Rapid urbanization in urban agglomerations has resulted in serious degradation of ecosystem functions and deterioration of ecosystem health, which hinders the current process of new-type urbanization and ecological civilization construction in China. Healthy ecosystem in urban agglomerations is closely related to the sustainability of urban agglomerations. The scientific assessment of the ecosystem health status has important practical significance for the formulation of macro-control policies for ecosystem health in the urban agglomerations, but the current studies about the ecosystem health evaluation in urban agglomerations were still insufficient. An increasing number of studies have been
\end{abstract}

基金项目: 国家自然科学基金(42001187); 地表过程与资源生态国家重点实验室开放基金资助项目(2021-KF-03)

收稿日期: 2020-12-09; 网络出版日期:2021-08- 17

* 通讯作者 Corresponding author.E-mail: zhaoxl@ cug.edu.cn 
carried out on the theories, concepts, spatiotemporal differentiation characteristics, and influencing factors of ecosystem health, but few studies have included the results of ecosystem services assessment based on InVEST model into the theoretical framework of ecosystem health assessment. Ecosystem services assessment is an important part to reflect the health status of the ecosystem. Ecosystem services assessment based on InVEST model can well reflect the structure, function, and ecological process of ecosystem services, and realize the spatial and dynamic quantitative assessment of ecosystem services. How to integrate ecosystem services into the framework of ecosystem health assessment has become a hot topic of the current studies. Based on the ecosystem services evaluated by InVEST model, this study constructed the ecosystem health assessment framework system of “Vigor-Organization-Resilience-Ecosystem Services”, and evaluated the ecosystem health level in the Middle Reaches of the Yangtze River Urban Agglomerations (MRYRUA) with multi-source data. The results showed that: (1) the ecosystem health index in Jianghan Plain, Dongting Lake Plain, Wuhan, Changsha, Nanchang, and other surrounding counties was mostly below 0.35 , while the ecosystem health index of the surrounding mountainous counties was more than 0.65 . In addition, the ecosystem health index of units along major traffic routes was lower than that of other regions. The overall ecosystem health status in the MRYRUA deteriorated during the study period, mainly in the core areas of these urban agglomerations. (2) The ecosystem health in the MRYRUA showed significantly spatial dependence during the study period, the high-valued areas of ecosystem health were mainly distributed in the surrounding mountainous areas and the central Luoxiao Mountains, while the low-valued areas of ecosystem health were mainly distributed in the plain areas, the surrounding areas of key cities, and the areas along the main traffic routes. The results of the study can provide scientific support for ecosystem health assessment in other regions and ecosystem health protection policy-making in the MRYRUA.

Key Words : ecosystem health; ecosystem services; InVEST model; spatiotemporal patterns; the Middle Reaches of the Yangtze River Urban Agglomerations

日益严重的生态环境问题引发了人类对健康问题与生态问题的深人思考,健康的概念逐渐从人类转移到 生态系统上 ${ }^{[1]}$ 。可持续发展战略、生态文明建设以及“One Health”理念的提出表明人类对人地关系认识进一 步深化 ${ }^{[2]}$ 。生态系统健康概念的提出扩展了人类对自身健康和疾病来源的理解, 可以构建人类健康、人类活 动和生态系统变化之间关联 ${ }^{[3]}$ 。构建科学的生态系统健康评估理论框架是准确评估生态系统健康的前提, 是制定生态系统健康宏观调控政策的基础, 但是以往生态系统健康评估仍存在不足。以往研究更多地关注生 态系统的完整性和可持续性,生态系统服务是反映生态系统健康状况的重要组成部分, 然而如何把生态系统 服务纳人生态系统健康评估框架需要进一步的进行探讨。此外, 在当前生态文明和美丽中国建设背景下, 选 择快速城镇化的城市群地区作为研究对象, 评估城市群地区生态系统健康状况的研究并不多见。因此, 有必 要对生态系统健康评估框架的构建以及城市群地区生态系统健康时空演化特征进行深人分析。

生态系统健康是指在一定时空范围内, 不同类型生态系统空间镶嵌而成的地域综合体在维持各生态系统 自身健康的前提下, 提供丰富的生态系统服务的稳定性和可持续性 ${ }^{[4]}$ 。在过去几十年, 生态系统健康领域取 得了迅速发展, 并在生态系统健康的理论、概念和评价方法以及影响因素等方面取得了一定进展, 主要体现在 以下几个方面: (1)在理论和概念方面, 虽然生态系统健康的概念仍未达成共识 ${ }^{[1]}$, 但是生态系统健康的理论 和内涵仍然得到了一定的丰富和拓展。由强调生态系统的自然生态方面转型为综合考虑生态系统自身健康 以及其满足人类需求和愿望的程度和社会经济等方面 ${ }^{[5-7]}$ 。(2)在评价方面, 以往研究主要采用指示物种 法 $^{[8-9]}$ 和指标体系法 ${ }^{[10-11]}$ 对生态系统健康进行了多尺度的测度。前者主要采用种群数量、生物量以及其他 重要的生理指标来间接评估生态系统健康状况, 后者通常采用基于生态系统活力-组织力-弹性-生态系统服务 以及压力-状态响应等理论框架进行生态系统健康评估 ${ }^{[10-12]}$ 。生态系统服务是生态系统健康评估的核心， 可以很好地连接自然环境和人类福祉 ${ }^{[13]}$ 。关注人类福祉是生态系统健康新的研究指向, 生态系统健康评估 
过程中纳人生态系统服务是明晰生态系统与人类福祉之间内在综合关联的有效途径 ${ }^{[14-15]}$ 。当前生态系统健 康评估更加重视研究具体的生态过程, 并侧重关注生态格局或生态过程造成的人类健康问题 ${ }^{[16]}$ 。而基于 InVEST 模型的生态系统服务评估可以很好地反映生态系统服务结构功能和生态过程, 实现生态系统服务定 量评估的空间化和动态化 ${ }^{[14,17]}$ 。但是,如何把基于 InVEST 模型的生态系统服务与传统的 “生态系统活力-组 织力-弹性” 逻辑关系有机衔接需要进一步探索。在当前长江经济带共抓大保护, 不搞大开发背景下研究长江 中游城市群地区生态系统健康时空特征对实现经济高质量发展具有重要实践指导意义。当前,城市群日益成 为新型城镇化的主体形态和现代化建设的重要载体, 以往文献在流域生态系统健康、城市生态系统健康等方 面进行了全面的研究, 但是很少有研究探索城市群地区生态系统健康状态时空分异特征 ${ }^{[6,18-19]}$ 。

综上所述, 以往研究对生态系统健康理论、概念、时空分异特征和影响因素等方面开展了丰富的实践研 究, 但鲜有研究把基于 InVEST 模型的生态系统服务评价结果纳人生态系统健康评估理论框架中。另外, 当 前城市群地区逐渐成为中国城镇化进程的主体形态,而系统探索城市群地区生态系统健康状态时空分异特征 的研究较为少见。鉴于此, 本研究拟在以往研究基础上对生态系统健康评估框架进行完善, 并且结合多源数 据, 对长江中游城市群地区生态系统健康进行评估以及时空演化特征进行实证分析, 以期为长江中游城市群 地区生态系统健康保护政策制定提供科学参考。

\section{1 研究区概况与数据来源}

\section{1 研究区概况}

本研究中长江中游城市群范围包括湖北省的武汉 城市圈和宜昌-荆州-荆门城市群、湖南省的长株潭城市 群和江西省的环鄱阳湖城市群(图 1)。长江中游城市 群处于中国地形梯度中第二阶梯向第三阶梯过渡地带, 地形条件复杂。周边被群山环绕, 中部的罗霄山脉将江 西和湖南分割, 鄱阳湖平原、江汉平原和洞庭湖平原沿 长江广泛分布。气候类型属于亚热带季风性气候, 夏季 高温多雨, 冬季温和少雨, 是我国的粮食主产区。长江 中游城市群承东启西、连南接北, 是实施促进中部地区 崛起战略和长江经济带战略、全方位深化改革开放和推 进新型城镇化先行区、内陆开放合作示范区和“两型” 社会建设引领区, 在我国区域发展格局中占有重要地 位。长江中游城市群城镇化的快速发展对生态系统产 生的胁迫作用日益突显,严重威胁城市群地区的可持续 发展。由此可见,科学测度长江中游城市生态系统健康

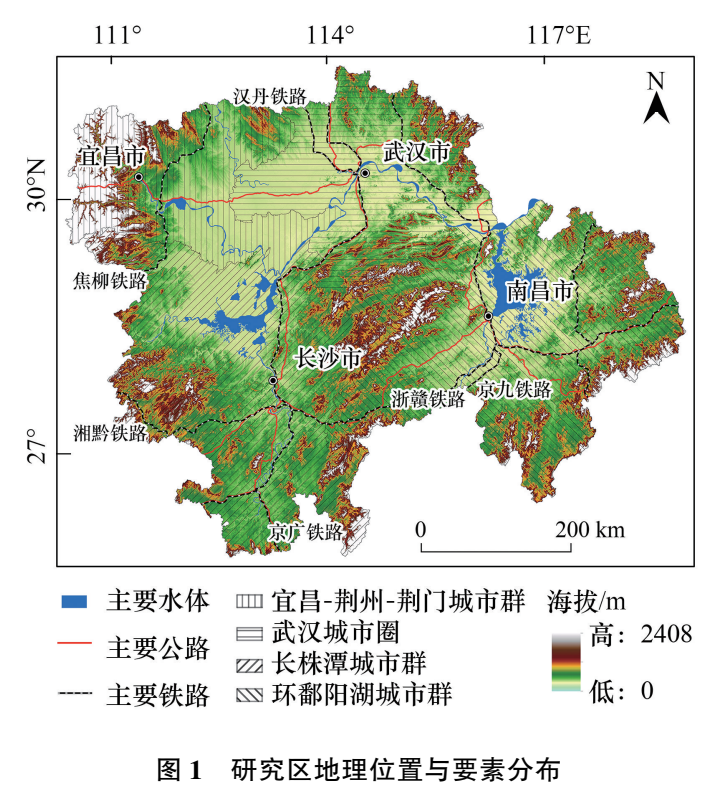

Fig. 1 Geographical location and element distribution of the study area 时空演变特征可以对长江中游城市群生态系统健康保 护政策制定具有重要意义。

\section{2 数据来源}

本研究涉及的自然地理数据包括土地利用数据、交通数据、DEM 高程数据、气象、土壤和植被覆盖; 社会 经济数据包括粮食产量, 具体的来源和描述见表 1 。

\section{2 研究方法}

准确评估长江中游城市群地区生态系统健康状况, 是分析其时空特征以及制定有效生态系统健康保护政 策的前提条件。本研究首先构建了 “生态系统活力-生态系统组织力-生态系统弹性-生态系统服务” 生态系统 
健康评估理论框架, 然后基于多源数据分别测度综合生态系统服务指数、生态系统活力、生态系统组织力和生 态系统弹性,最后对长江中游城市群生态系统健康时空特征进行测度。结合全局 Moran's $I$ 指数和 Getis-Ord $\mathrm{G}_{\mathrm{i}}{ }^{*}$ 指数对长江中游城市群生态系统健康时空演化特征进一步分析。

\section{表 1 研究数据来源与描述}

Table 1 Data sources and descriptions

\begin{tabular}{|c|c|c|}
\hline $\begin{array}{l}\text { 数据类型 } \\
\text { Data type }\end{array}$ & $\begin{array}{l}\text { 数据格式 } \\
\text { Data formats }\end{array}$ & $\begin{array}{l}\text { 数据来源和描述 } \\
\text { Sources and descriptions }\end{array}$ \\
\hline $\begin{array}{l}\text { 土地利用/覆被变化数据 } \\
\text { Land use/land cover change data }\end{array}$ & GeoTIFF & $\begin{array}{l}\text { 中国科学院资源环境科学数据中心 ( http://www. resdc.cn), 空间分辨 } \\
\text { 率是 } 30 \mathrm{~m} \times 30 \mathrm{~m} \text { 。 }\end{array}$ \\
\hline $\begin{array}{l}\text { 高程数据 } \\
\text { Digital elevation model }\end{array}$ & GeoTIFF & $\begin{array}{l}\text { 中国科学院计算机网络信息中心地理空间数据云系统 (http://www. } \\
\text { gscloud.cn)。 }\end{array}$ \\
\hline $\begin{array}{l}\text { 气象数据 } \\
\text { Climate data }\end{array}$ & GeoTIFF & $\begin{array}{l}\text { 年平均气温来源于中国科学院资源环境科学数据中心 ( http://www. } \\
\text { resdc.cn); 年均潜在蒸散量来源于全球干早和潜在蒸散数据库 } \\
\text { (http://www.cgiar-csi.org/data/global-aridity-and-pet-database) }\end{array}$ \\
\hline $\begin{array}{l}\text { 土壤数据 } \\
\text { Soil properties }\end{array}$ & MDB & " 黑河计划数据管理中心" (http://westdc.westgis.ac.cn)。 \\
\hline $\begin{array}{l}\text { 植被覆盖指数 } \\
\text { Normalized Difference Vegetation Index }\end{array}$ & GeoTIFF & $\begin{array}{l}\text { 中国科学院资源环境科学数据中心 ( http://www. resdc. cn/DataList. } \\
\text { aspx), 空间分辨率是 } 1 \mathrm{~km} \times 1 \mathrm{~km}_{\text {。 }}\end{array}$ \\
\hline $\begin{array}{l}\text { 交通数据 } \\
\text { Traffic data }\end{array}$ & Shipfile & $\begin{array}{l}2015 \text { 年交通数据源于国家基础地理信息中心 ( NGCC) ( http://ngcc. } \\
\text { sbsm. gov.cn/), } 1995 \text { 年、2000 年、2005 年、和 } 2010 \text { 年份交通数据通过最 } \\
\text { 新版交通图矢量化获取。 }\end{array}$ \\
\hline $\begin{array}{l}\text { 社会经济数据 } \\
\text { Socioeconomic data }\end{array}$ & Excel & 1996-2016 年湖北省、湖南省和江西省统计年鉴 \\
\hline
\end{tabular}

\section{1 生态系统健康评估理论框架构建}

本研究对 Costanza 等提出的生态系健康评估框架" Vigor-Organization-Resilience Evaluation System"进行了 丰富和拓展,创新地把基于 InVEST 模型测度的生态系统服务纳人生态系统健康评估理论框架,构建基于“生 态系统活力-生态系统组织力-生态系统弹性-生态系统服务” 的生态系统健康评估框架体系 ${ }^{[5,20]}$ (图 2)。参考 以往研究 Peng 等和 Pan 等, 本研究中生态系统健康主要通过两个方面进行评估:生态系统自然健康和综合生 态系统服务指数 (公式 1 ${ }^{[21-22]}$ 。其中生态系统自然健康包括生态系统活力、生态系统组织力和生态系统弹 性三个方面(公式 2) ${ }^{[23]}$ 。综合生态系统服务指数由供给服务、调节服务、支持服务和文化服务综合测 度 ${ }^{[20,24]}$ 。具体计算公式如下:

$$
\mathrm{EHI}_{i t}=\sqrt{P H_{i t} \times \mathrm{CESI}_{i t}}
$$

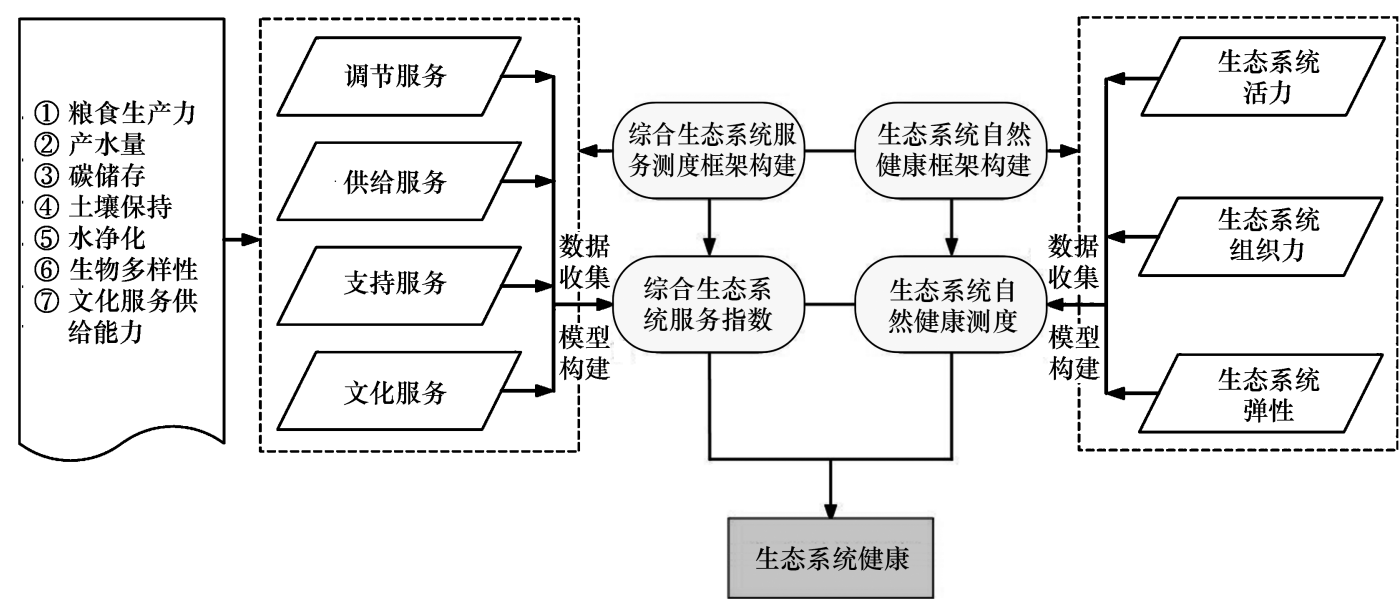

图 2 生态系统健康评估概念框架

Fig.2 Conceptual framework for ecosystem health assessment 


$$
P H_{i t}=\sqrt[3]{V_{i t} \times O_{i t} \times R_{i t}}
$$

式中, $\mathrm{EHI}_{i t}$ 是第 $i$ 个单元 $t$ 时刻的生态系统健康指数; $P H_{i t}$ 是第 $i$ 个单元 $t$ 时刻的生态系统自然健康指数; CESI ${ }_{i t}$ 是第 $i$ 个单元 $t$ 时刻的综合生态系统服务指数; $V_{i t}, O_{i t}$ 和 $R_{i t}$ 分别是第 $i$ 个单元 $t$ 时刻的生态系统活力、生 态系统组织力和生态系统弹性。由于健康是一个相对概念, 本研究参考欧维新等 (2018) 的研究, 把生态系统 健康均值设为生态系统健康状况一般水平 ${ }^{[23]}$ 。将评价结果分为 5 个等级: 良好 $(0.65-1)$ 、较好 $(0.55-$ $0.65) 、$ 一般 $(0.45-0.55)$ 、较差 $(0.35-0.45)$ 、差 $(0-0.35)$ 。

\section{2 综合生态系统服务指数测度}

本研究基于 InVEST 模型测度粮食生产力、产水量、碳储存、土壤保持、水净化、生物多样性和文化服务供 给能力等方面生态系统服务供给能力 ${ }^{[20]}$ 。具体计算方法见表 2 。

表 2 生态系统服务量化方法

Table 2 Methods of ecosystem services quantification

\begin{tabular}{lll}
\hline $\begin{array}{l}\text { 生态系统服务 } \\
\text { Ecosystem service }\end{array}$ & $\begin{array}{l}\text { 计算方法 } \\
\text { Method }\end{array}$ & $\begin{array}{l}\text { 计算公式 } \\
\text { Calculation }\end{array}$ \\
\hline & & $\begin{array}{l}\text { 基于单位面积耕地生物量占耕 } \\
\text { 他总生物量的比重对粮食产量 } \\
\text { Supplying services } \\
\text { 统计数据进行空间化 }\end{array}$ \\
& 粮食生产能力 \\
& & 基于水量平衡原理, 同时考虑气 \\
调节服务 & 候、地形、植被、土壤等因素, 定 \\
Regulating services & 产水能力 & 量评估不同生态系统的产水 \\
& & 能力 \\
& &
\end{tabular}

综合考虑地上生物量、地下生物 碳储存能力 量、土壤和死亡有质 4 个碳库的 生态系统碳储量 ${ }^{[24]}$ 。

通过估算植被和土壤对径流中 水净化能力 $\quad N 、 P$ 营养盐截留量来反映水净 化能力 ${ }^{[26]}$ 。

参考通用土壤流失方程, 综合考

支持服务

Supporting services

土壤保持能力

虑了地块本身拦截上游沉积物 的能力 ${ }^{[27]}$ 。

生境质量

运用 InVEST 模型中的生境质量 模块对生境质量进行评估 ${ }^{[28]}$ 。

基于生态系统服务供需矩阵测 度文化服务功能 ${ }^{[29]}$ 。
$G P_{i j}=G P_{j} \times \mathrm{VCI}_{i j} / \sum_{i=1}^{n} \mathrm{VCI}_{i j}$

式中: $G P_{i j}$ 代表第 $j$ 个行政单元的第 $i$ 个格网单元粮食产量; $G P_{j}$ 代表第 $j$ 个行政单元的粮食产量统计数据; $\mathrm{VCI}_{i j}$ 代表第 $j$ 个行政 单元的第 $i$ 个格网单元生物量; $n$ 是研究区格网单元的数量

$Y(i)=\left(1-\frac{\operatorname{AET}(i)}{P(i)}\right) \times P(i)$

式中: $Y$ 是年平均产水量; AET $(i)$ 是第 $i$ 个格网年实际蒸散发 量; $P(i)$ 第 $i$ 个格网年均降水量

$C S_{\text {total }}=C S_{\text {above }}+C S_{\text {below }}+C S_{\text {soil }}+C S_{\text {dead }}$

式中: $C S_{\text {total }}$ 为总碳储量; $C S_{\text {above }}$ 为地上生物碳储量; $C S_{\text {below }}$ 为地 下生物碳储量; $C S_{\text {soil }}$ 为土壤碳储量; $C S_{\text {dead }}$ 为死亡有机物碳 储量。

$\mathrm{ALV}_{i}=\mathrm{HSS}_{i} \times \operatorname{pol}_{i}$

式中: $\operatorname{ALV}_{i}$ 是第 $i$ 个格网单元载荷值; $\operatorname{pol}_{i}$ 是第 $i$ 个格网单元输 出系数; $\mathrm{HSS}_{i}$ 是第 $i$ 个格网单元水文敏感性得分值

$\mathrm{USLE}_{i}=R_{i} \cdot K_{i} \cdot L S_{i} \cdot\left(1-C_{i} P_{i}\right)$

式中: $\mathrm{USLE}_{i}$ 是单位面积土壤保持量; $R_{i}$ 是第 $i$ 个格网单元降雨 侵蚀因子 $\left[\mathrm{MJ} \mathrm{mm} \mathrm{hm}{ }^{-2} \mathrm{~h}^{-1}\right] ; K_{i}$ 是第 $i$ 个格网单元土壤可蚀性 因子; $L_{i}$ 和 $S_{i}$ 分别是第 $i$ 个格网单元坡长坡度因子; $C_{i}$ 和 $P_{i}$ 分别 是第 $i$ 个格网单元植被覆盖管理因子和土壤保持措施因子。

$\mathrm{Q}_{x j}=H_{j} \times\left(1-\left(D_{x j}^{z} /\left(D_{x j}^{z}+k^{z}\right)\right)\right)$

式中: $Q_{x j}$ 表示第 $x$ 个格网单元中第 $j$ 类土地利用 $/$ 覆被类型的生 境质量指数; $H_{j}$ 为土地利用/覆被类型 $j$ 的生境适宜度; $D_{x j}$ 为第 $x$ 个格网单元中土地利用 $/$ 覆被类型 $j$ 生境退化度; $k$ 为半饱和 常数, 取最大退化度的一半; $z$ 为归一化常量, 是模型默认参数

$S_{i}=\sum_{j=1}^{n}\left(\mathrm{LUA}_{j, t} \times S M_{j, t}\right) / \sum_{j=1}^{n} \mathrm{LUA}_{j, t}$

式中: $S_{i}$ 第 $i$ 个单元中文化服务功能指数; $S M_{j, t}$ 是第 $j$ 种土地利 用类型 $t$ 时的文化服务供给能力矩阵; $\mathrm{LUA}_{j, l}$ 是第 $j$ 种土地利用 类型 $t$ 时面积; $n$ 是土地利用类型的数量 
不同生态系统服务侧重于衡量生态系统供给能力的不同方面,为了测度综合生态系统服务,本研究将不 同种类生态系统服务进行标准化 (公式 3 和 4)。根据不同生态系统服务的具体含义, 本研究中只有 $\mathrm{N}$ 和 $\mathrm{P}$ 输 出量为负向指标, 其他指标均为正向指标。基于标准化后的生态系统服务,采用层次分析方法进行权重赋值, 最后采用综合得分法(公式 5), 计算综合生态系统服务指数,具体计算公式如下:

正向因子:

$$
E S_{i j}^{\prime}=\frac{E S_{i j}-\min \left\{E S_{1 j}, \cdots, E S_{n j}\right\}}{\max \left\{E S_{1 j}, \cdots, E S_{n j}\right\}-\min \left\{E S_{1 j}, \cdots, E S_{n j}\right\}}
$$

负向因子:

$$
E S^{\prime}{ }_{i j}=\frac{\max \left\{E S_{1 j}, \cdots, E S_{n j}\right\}-E S_{i j}}{\max \left\{E S_{1 j}, \cdots, E S_{n j}\right\}-\min \left\{E S_{1 j}, \cdots, E S_{n j}\right\}}
$$

式中, $E S_{i j}{ }^{\prime}$ 是标准化后的第 $i$ 个格网单元的第 $j$ 种生态系统服务; $E S_{i j}$ 是第 $i$ 个格网单元的第 $j$ 种生态系统服 务; $\max \left(E S_{j}\right)$ 和 $\min \left(E S_{j}\right)$ 分别是所有单元中的最大值和最小值。

$$
\operatorname{CESI}_{i}=\sum_{j=1}^{n} W_{j} \times E S^{\prime}{ }_{i j}
$$

式中: CESI 是第 $i$ 个格网单元的综合生态系统服务指数; $W_{j}$ 是基于层次分析法计算得出的各种生态系统服务类 型的权重系数; $E S_{i j}{ }^{\prime}$ 是标准化后的第 $i$ 个格网单元的第 $j$ 种生态系统服务; $n$ 是本研究中生态系统服务类型。

\section{3 生态系统自然健康指数测度}

生态系统自然健康通常通过生态系统活力、生态系统组织力和生态系统弹性来表征 ${ }^{[11]}$ 。生态系统活力 用来描述生态系统的代谢和初级生产力, 本研究中采用归一化植被指数来表征生态系统活力 ${ }^{[13]}$ 。与以往研 究不同的是, 本研究并不是直接基于归一化植被指数对生态系统活力进行计算, 而是依据生态环境状况评价 技术规范 (HJ 192-2015), 通过计算不同土地利用类别的比例来计算植被覆盖度, 具体计算公式参考 Meng 等 $(2018)^{[30]}$ 。该方法的优点在于量化了土地利用变化引起的植被覆盖度变化,能够从土地利用变化的角度 更好地反映生态系统活力。生态系统组织力主要是用来描述生态系统结构的稳定性,一般来说,生态系统组 织力主要是由与景观空间异质性和景观连通性相关的景观格局指数表征 ${ }^{[11,23]}$ 。本研究拟选择 Shannon 多样 性指数和面积加权平均斑块分形指数来表征景观空间异质性。通过整个景观和生境的联通性共同表征景观 连通性, 具体地通过景观破碎化指数和景观蔓延度指数来表征整个景观的连通性, 通过林地、水域以及湿地的 破碎化指数和景观曼延度指数来表征生境连通性。最后基于专家打分法对不同景观格局指数进行权重赋值， 计算得出区域生态系统组织力水平,具体计算公式参考欧维新等和 Peng 等 ${ }^{[21,23]}$ 。生态系统弹性主要是用来 表征生态系统在遭遇外部干扰后恢复其原有结构和功能的能力。基于专家知识以及以往研究,本研究拟对不 同土地利用类型进行弹性系数赋值, 最后基于土地利用类型面积加权法, 计算得出区域生态系统弹性指数, 具 体计算公式参考 Peng 等和 Zhang 等 ${ }^{[31-32]}$ 。

\section{4 探索性空间数据分析}

为了进一步分析长江中游城市群生态系统健康在空间上的演化规律, 本研究采用探索性空间数据分析 (Exploratory Spatial Data Analysis,ESDA) 方法来探测研究期间长江中游城市群生态系统健康在空间上的演化 特征。其中本研究采用全局 Moran's I 指数来探测生态系统健康在长江中游城市群地区的空间关联以及空间 差异程度,采用 Getis-Ord $\mathrm{G}_{i}^{*}$ 指数来探测局部尺度生态系统健康的空间异质性特征以及空间分布格局特征。 具体地, 全局 Moran's I 指数在 GeoDa 095i 中运行, 而 Getis-Ord $G_{i}{ }^{*}$ 指数在 ArcGIS 10.3 中运行 ${ }^{[33]}$ 。

\section{3 结果与分析}

3.1 1995一2015 年长江中游城市群土地利用/覆被变化特征

林地是长江中游城市群最主要的土地利用类型,其次是耕地和水域。1995-2015 年, 林地面积所占比例 
分别为 $49.03 \% 、 49.01 \% 、 48.93 \% 、 48.79 \%$ 和 $48.53 \%$, 耕地占比分别为 $38.79 \% 、 38.42 \% 、 37.95 \% 、 37.22 \%$ 和 $36.77 \%$ 。研究期间长江中游城市群地区耕地和林地面积呈现出持续降低趋势。1995-2015 年耕地和林地净 减少面积分别为 $6153.80 \mathrm{~km}^{2}$ (占土地总面积的 $2.02 \%$ ) 和 $1523.16 \mathrm{~km}^{2}$ (占土地总面积的 $0.50 \%$ )。城市化和 工业化的快速推进, 极大地推动了长江中游城市群地区建设用地的扩张。1995-2000 年、2000-2005 年、 2005-2010 年和 2010-2015 年间建设用地增速分别为 9.83\%、14.45\%、25.91\% 和 $18.08 \%$ 。其他土地利用类 型, 如水域和湿地在研究期间也有所增加。1995-2000、2000-2005、2005-2010、2010-2015 年间分别有 $12756.85 \mathrm{~km}^{2} 、 11871.59 \mathrm{~km}^{2} 、 14180.97 \mathrm{~km}^{2}$ 和 $18469.05 \mathrm{~km}^{2}$ (分别占土地总面积的 $4.19 \% 、 3.90 \% 、 4.65 \%$ 和 $6.06 \%)$ 的土地发生了变化。其中,林地和耕地之间的变化最为频繁, 分别占变化总面积的 $49.63 \% 、 28.30 \%$ 、 $28.02 \%$ 和 $40.68 \%$ 。1995-2000、2000-2005、2005-2010、2010-2015 年间, 分别有 $1161.34 \mathrm{~km}^{2} 、 1138.48$ $\mathrm{km}^{2} 、 1924.00 \mathrm{~km}^{2}$ 和 $2247.45 \mathrm{~km}^{2}$ 的耕地转化为建设用地, 而只有 $525.26 \mathrm{~km}^{2} 、 369.69 \mathrm{~km}^{2} 、 329.88 \mathrm{~km}^{2}$ 和 969.75 $\mathrm{km}^{2}$ 的建设用地转化为耕地, 表明耕地和建设用地的相互转换中存在强烈的不平衡。

3.2 1995-2015 年长江中游城市群综合生态系统服务指数时空分布特征

1995 年、2000 年、2005 年、2010 年和 2015 年长江中游城市群综合生态系统服务指数平均值分别为 $0.452 、 0.438 、 0.442 、 0.439$ 和 0.443 。研究期间, 长江中游城市群生态系统综合服务指数总体呈波动降低趋势。 湖北省西部的巫山以及北部的大别山、湖南省中西部的雪峰山和南部的南岭、江西省东部的武夷山脉以及江 西和湖南两省之间的罗霄山脉综合生态系统服务指数总体高于 0.50 (图 3)。洞庭湖平原、鄱阳湖平原、武汉 城市群、长株潭城市群和鄱阳湖城市群, 特别是一些主要城市周边的县域单元综合生态服务水平明显较低。 其中, 江汉平原和武汉城市圈的生态系统服务综合供给能力最低。山地生态系统在碳储存、水土保持、生物多 样性保护以及文化服务等方面具有绝对优势, 而平原地区生态系统具有较强的粮食生产功能。社会经济的快 速发展和城市化进程的快速推进,加剧了平原地区生态保护、城市化发展与土地利用转型之间的矛盾。1978 年启动的 “重点防护林带建设工程”、1998 年启动的 “天然林保护工程” 等生态系统服务保护工程, 以及毁林、 滥垦等土地利用活动频繁发生, 导致了长江中游城市群地区生态系统服务的权衡和协调问题日益加剧。

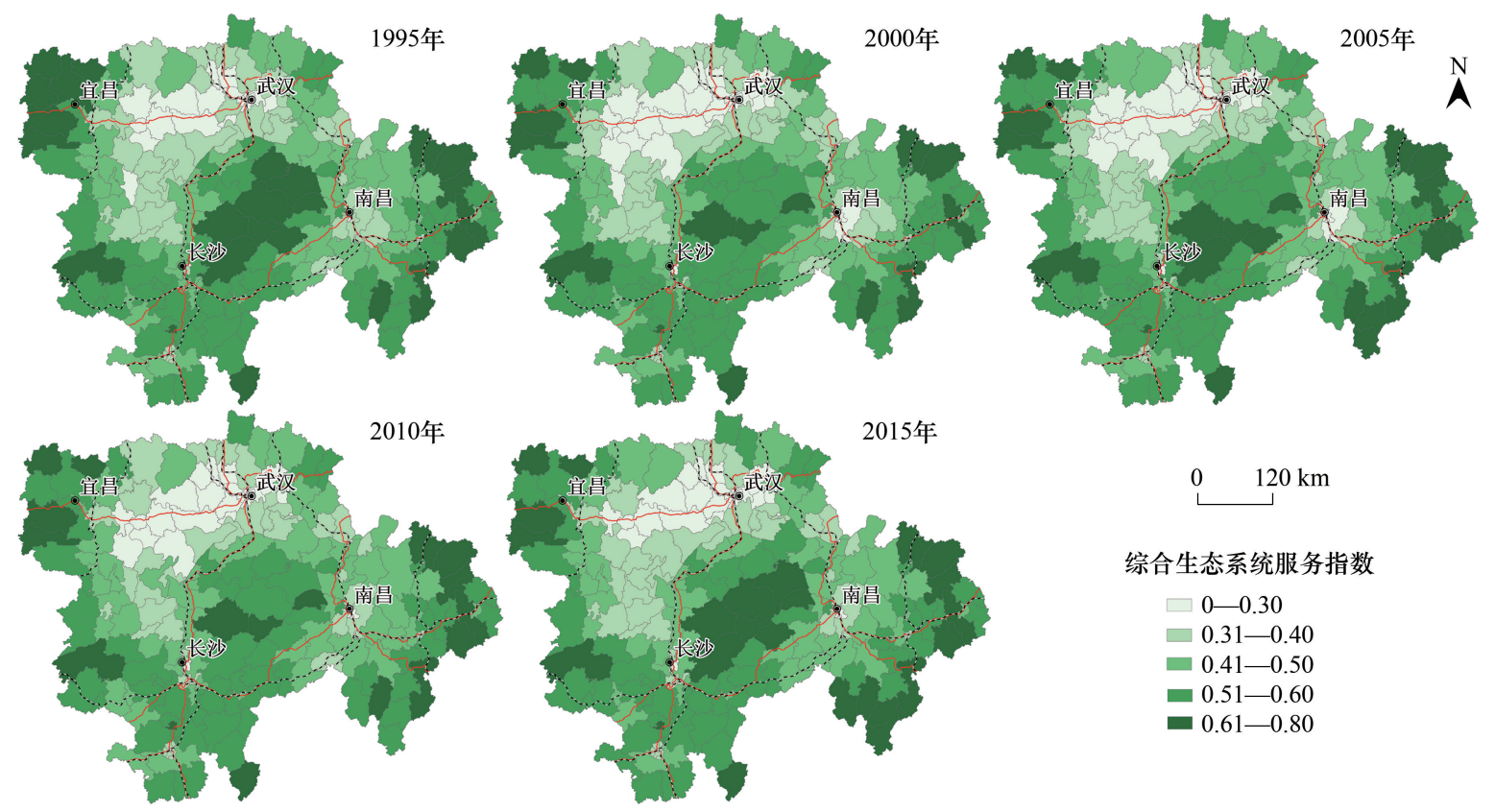

图 3 长江中游城市群综合生态系统服务指数时空分布

Fig.3 Spatiotemperal distribution patterns of comprehensive ecosystem services index in the Middle Reaches of the Yangtze River Urban Agglomerations (MRYRUA) 
3.3 1995-2015 年长江中游城市群生态系统自然健康指数时空分布特征

图 4 是 1995-2015 年长江中游城市群生态系统自然健康指数时空分布图。与生态系统组织力、活力和 恢复力的空间分布特征相似,周边山区生态系统自然健康水平明显高于平原地区。具体地, 周边山区以及中 部罗霄山脉生态系统自然健康值基本高于 0.75 , 平原地区生态系统自然健康值大多低于 0.45 。这主要是由于 平原地区的人类活动显著高于山区,对生态系统健康的干扰较高。1995 年、2000 年、2005 年、2010 年和 2015 年长江中游城市群生态系统自然健康平均水平分别为 $0.633 、 0.635 、 0.629 、 0.622$ 和 0.617 。可以发现, 长江中 游城市群地区的生态系统自然健康总体呈现出略微下降的趋势。

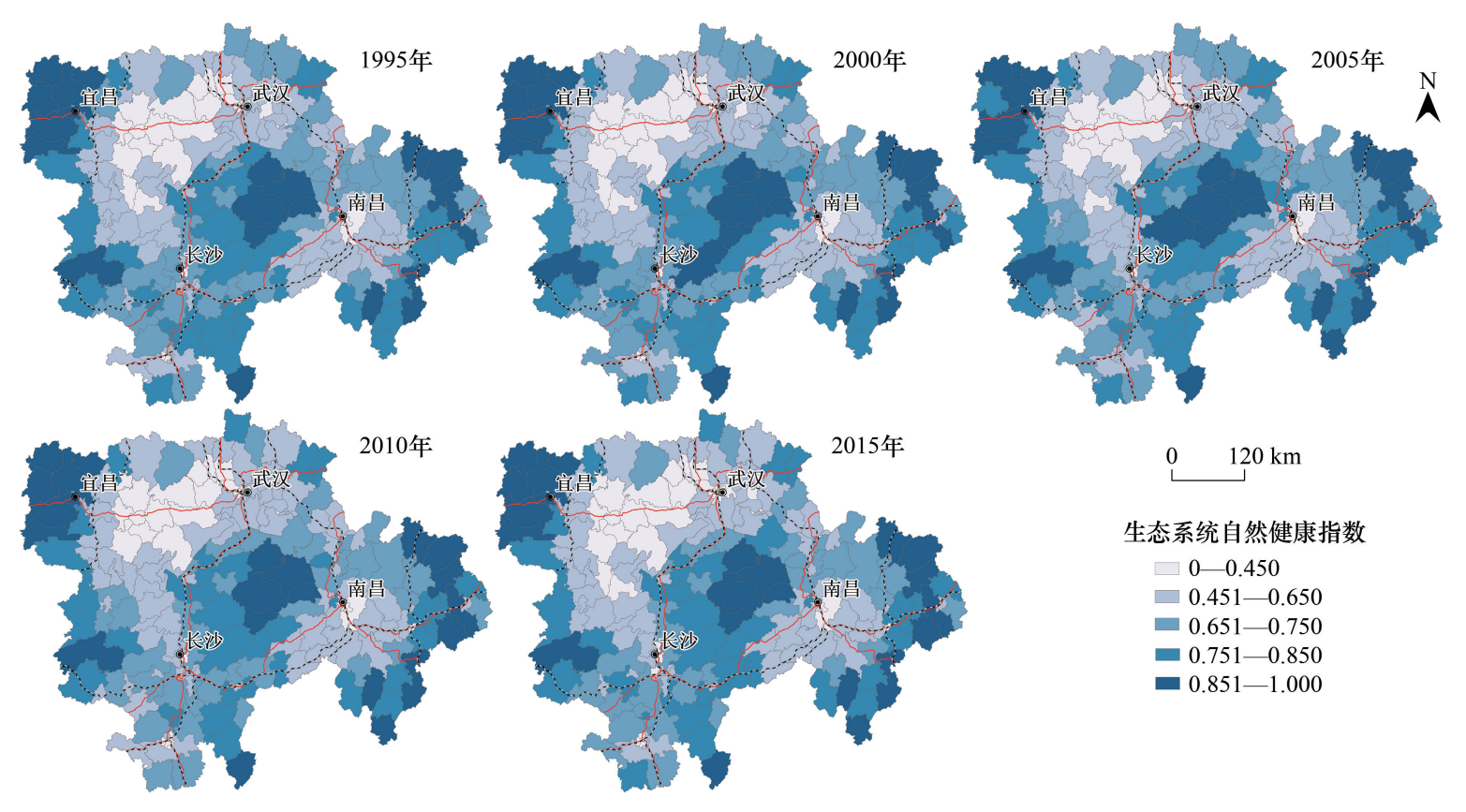

图 4 长江中游城市群生态系统自然健康水平时空分布

Fig.4 Spatiotemperal distribution patterns of ecosystem physical health level in the MRYRUA

3.4 1995-2015 年长江中游城市群生态系统健康时空分布特征

1995 年、2000 年、2005 年、2010 年和 2015 年长江中游城市群生态系统健康水平的平均值分别为 0.534 、 $0.527 、 0.526 、 0.523$ 和 0.522 , 总体上有所降低。研究期间, 低于生态系统健康指数均值的县域单元比例分别为 $55.07 \% 、 54.59 \% 、 53.62 \% 、 54.11 \%$ 和 $52.17 \%$ 。生态系统健康状态处于良好级别的县域单元比重最高 ( $>23 \%$ ), 其次是处于较好级别的县域单元比重( $>22 \%$ ), 处于差和较差级别的县域单元比重均低于 $18 \%$ 。在 空间分布方面, 可以发现长江中游城市群的生态系统健康水平具有显著的空间异质性(图 5)。在江汉平原、 洞庭湖平原以及武汉、长沙、南昌等周边县域单元的生态系统健康指数大多在 0.35 以下。周边山区县域的生 态系统健康指数多在 0.65 以上。另外, 主要交通路线沿线单元的生态系统健康指数也低于其他地区。可以 得出结论,生态系统健康状况和地形条件、交通条件、位置条件、经济发展水平密切相关。

全局 Moran's I 指数分析结果显示, 1995-2015 年间长江中游城市群生态系统健康水平全局 Moran's $I$ 指 数分别为 $0.640 、 0.644 、 0.645 、 0.628$ 和 0.628 , 而且在 0.001 水平上显著。可以看出研究期间长江中游城市群 生态系统健康存在显著空间依赖性。为了进一步分析其在空间上的集聚态势, 本研究采用 ArcGIS 10.3 中空 间统计工具 (Spatial Statistics Tools) 中热点分析 (Getis-Ord $G_{i}^{*}$ ) 工具绘制长江中游城市群县域单元综合生态 系统健康水平热点和冷点分布图 (图 6)。可以发现, 生态系统健康热点区主要分布在周边山区以及中部的罗 霄山脉,生态系统健康冷点区主要分布在平原地区、大城市周边地区以及主要的交通线路沿线地区。研究期 间平原地区生态系统健康状况下降明显, 特别是省会城市的周边地区以及主要交通干线沿线地区。另外结合 


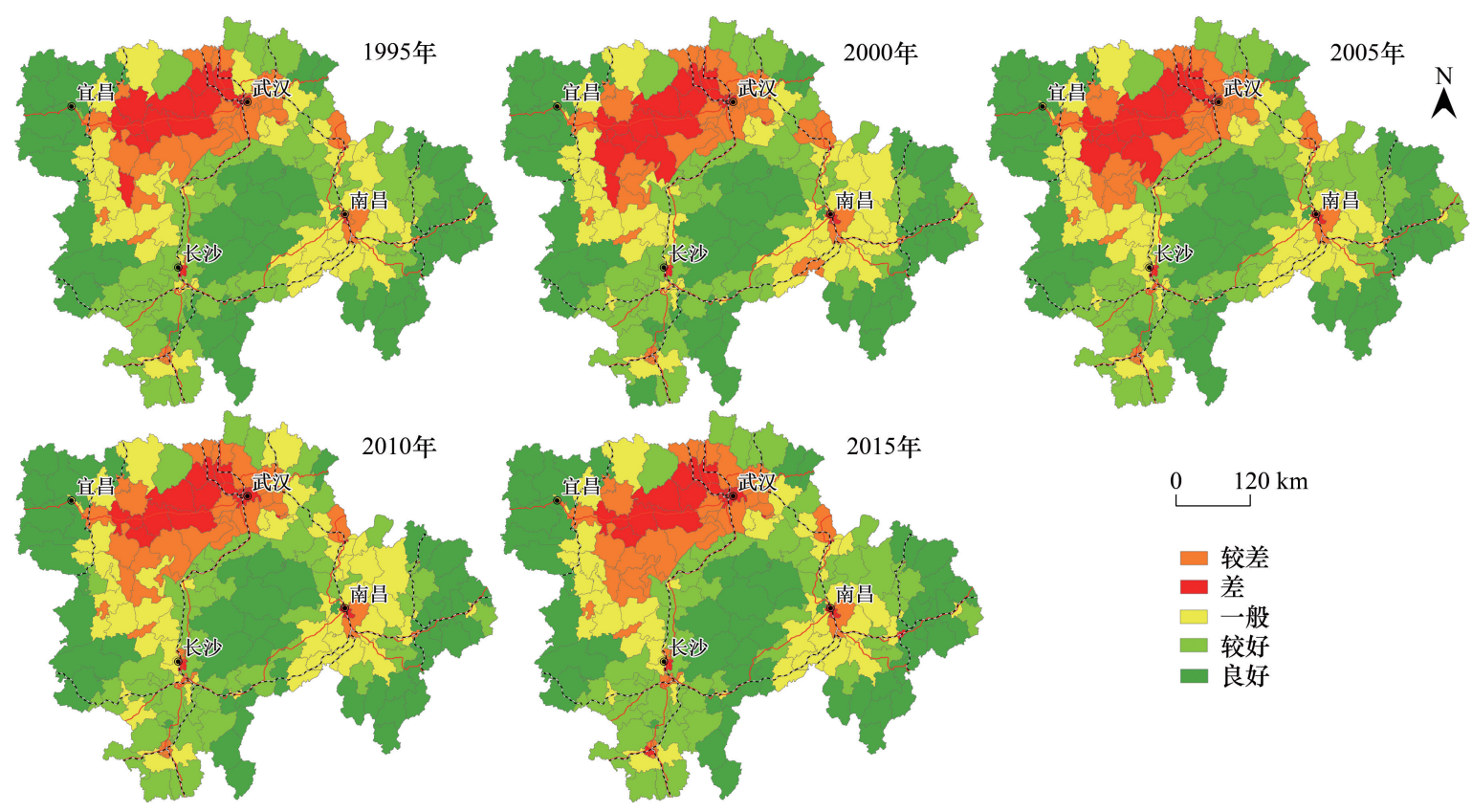

图 5 长江中游城市群生态系统健康水平时空分布

Fig.5 Spatiotemperal distribution patterns of ecosystem health level in the MRYRUA

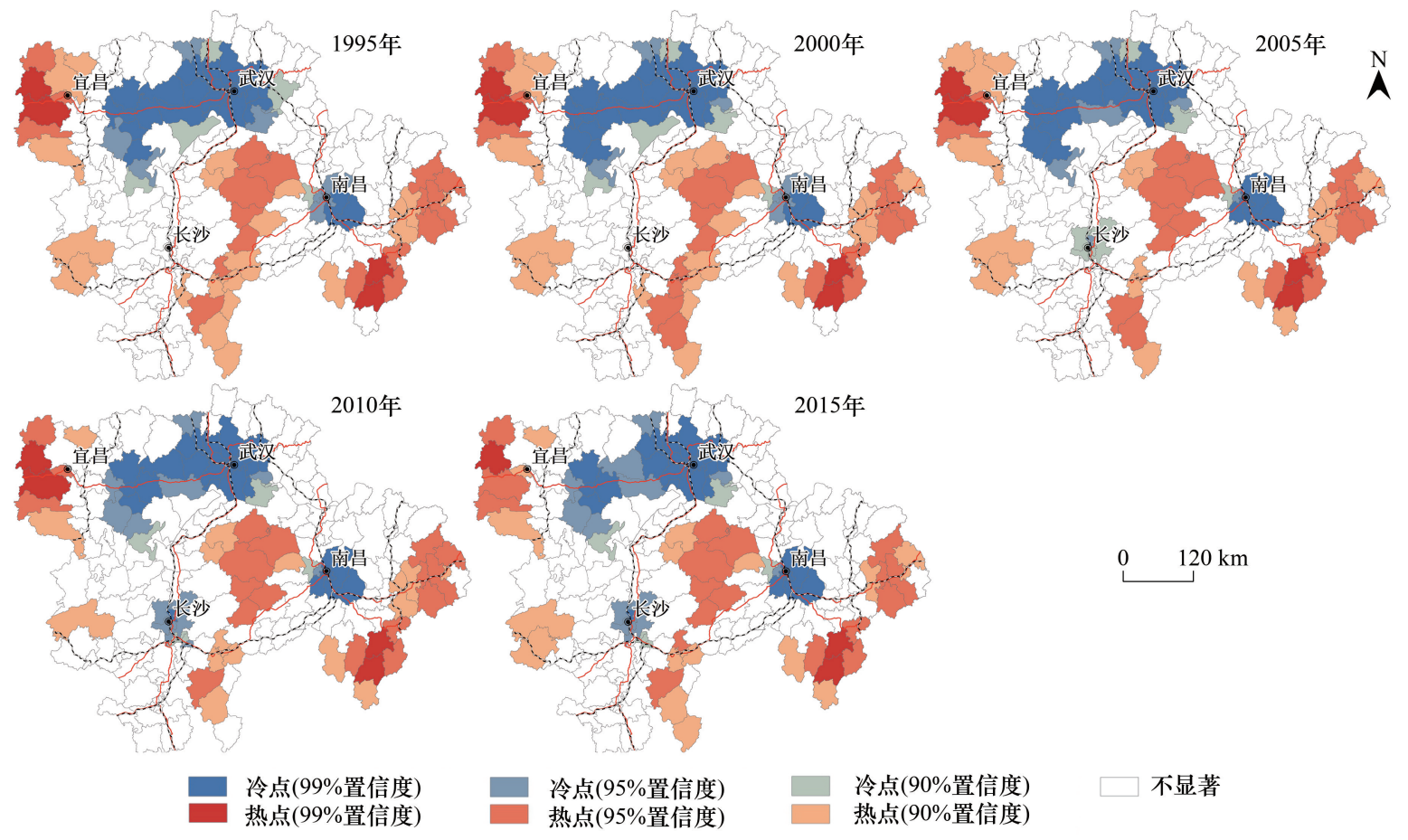

图 6 长江中游城市群生态系统健康水平热点和冷点分布

Fig.6 Spatiotemperal distribution patterns of hot spots and cold spots of ecosystem health level in the MRYRUA

长江中游城市群生态系统健康水平变化热点和冷点分布图 (图 7), 可以看出研究期间长江中游城市群生态系 统健康的恶化区域主要分布在城市群的核心地区。具体而言, 1995-2000 年间长江中游城市群生态系统健 康的冷点县区较少, 而且分布较为离散。2000-2005 年间,长江中游城市群的生态系统健康冷点县区主要分 
布在长沙和南昌市的周边地区。2005-2010 年间, 长江中游城市群的生态系统健康冷点县区主要分布在长 株潭城市群,热点县区主要分布在洞庭湖周边地区。2010-2015 年间,生态系统健康零点县区主要分布在宜 昌市周边地区以及洞庭湖周边地区。
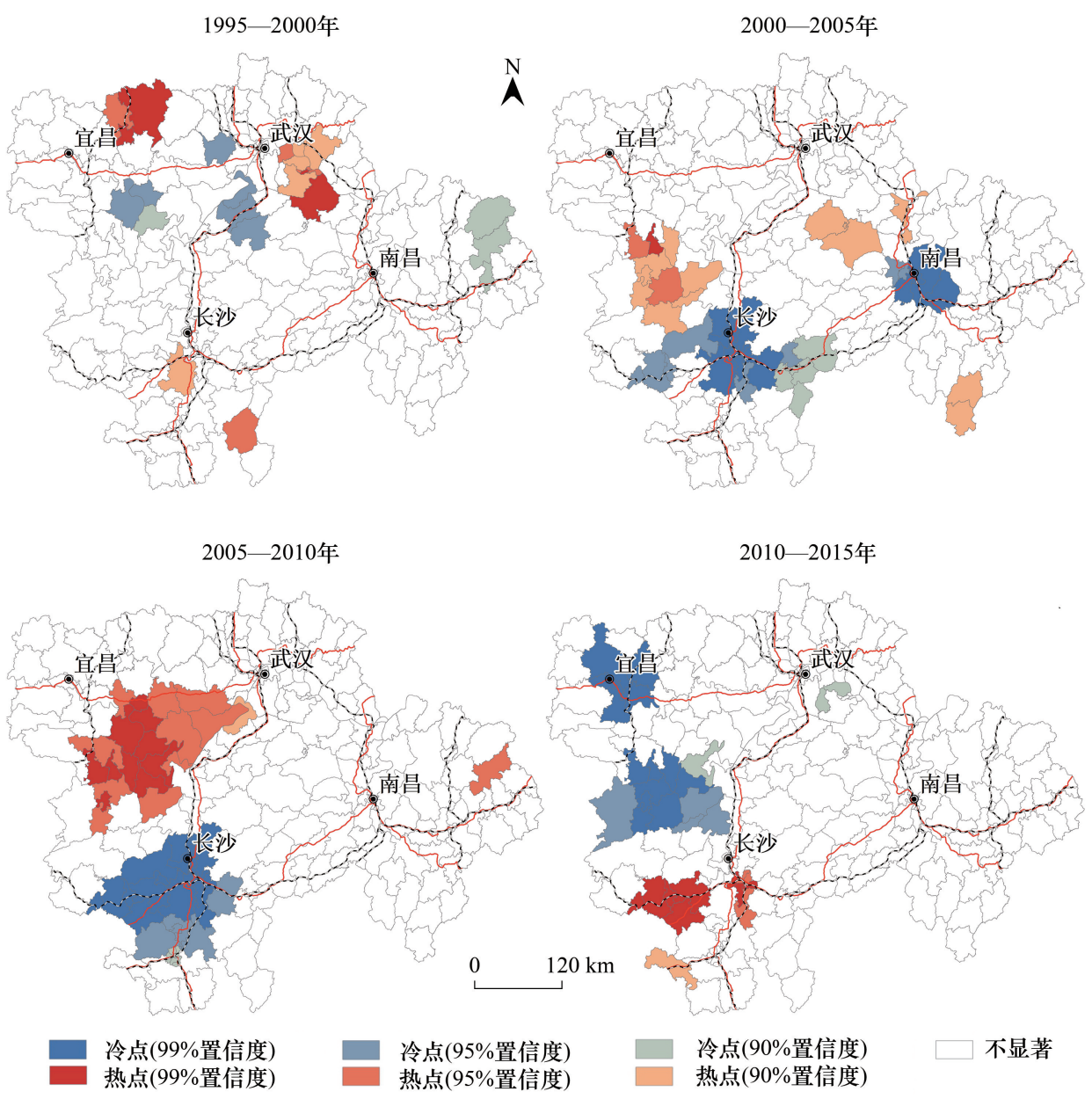

图 7 长江中游城市群生态系统健康水平变化热点和冷点分布

Fig.7 Spatiotemperal distribution patterns of hot spots and cold spots of ecosystem health changes in the MRYRUA

\section{4 结论与讨论}

\section{1 结论}

本研究基于 InVEST 模型测度的生态系统服务评估结果,构建了“生态系统活力-生态系统组织力-生态系 统弹性-生态系统服务” 的生态系统健康评估理论框架, 评估了 1995-2015 年长江中游城市群地区生态系统 健康水平时空特征, 结合全局 Moran's $I$ 指数和 Getis-Ord $\mathrm{G}_{i}^{*}$ 指数来测度研究期间长江中游城市群地区生态 系统健康水平时空演化特征。研究结果如下:

(1) 研究期间耕地和林地的变化呈现出持续的降低趋势,而建设用地呈现持续增加态势。建设用地占用 耕地面积显著高于建设用地复垦为耕地的面积;

(2) 研究期间长江中游城市群地区生态系统健康状况总体有所恶化, 由 1995 年的 0.534 降低到 2015 年 的 0.522 , 恶化区域主要分布在城市群的核心地区; 生态系统健康的高值区主要分布在周边山区以及中部的罗 霄山脉,生态系统健康的低值区主要分布在平原地区、大城市周边地区以及主要的交通线路沿线地区;

(3) 研究期间长江中游城市群地区生态系统健康水平存在显著的空间依赖性,生态系统健康水平变化冷 
点区域主要分在大城市周边地区;

\section{2 讨论}

生态系统健康测度方法多种多样, 总体上逐渐由强调生态系统自然生态方面转型为综合考虑生态系统自

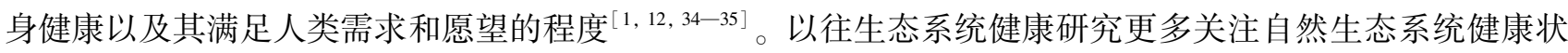
态, 而缺乏与人类社会维度的耦合关联研究。如何把基于 InVEST 模型的生态系统服务测度结果与传统的 “生态系统活力-生态系统组织力-生态系统弹性” 逻辑关系有机衔接是当前需要解决的问题。本研究将基于 InVEST 模型评估的生态系统服务 (提供服务、支持服务、调节服务和文化服务) 与生态系统健康评估联系起 来。在现有文献的基础上,本研究将粮食生产能力、产水量、碳储量、土壤保持、水净化、生物多样性和文化服 务供给等指标纳人生态系统健康评估中。借助综合生态系统服务指数,构建了生态系统健康评估框架 “生态 系统活力-生态系统组织力-生态系统弹性-生态系统服务”, 对长江中游城市群地区生态系统健康时空特征进 行评估, 为生态系统健康研究提供科学参考。为了更加准确的评估生态系统健康水平, 未来需要进一步加强 生态系统服务、生物多样性、生态文化健康以及可持续生计等方面和生态系统健康评估融合, 进一步丰富和完 善生态系统健康研究方法和手段 ${ }^{[14,16]}$ 。

\section{参考文献 (References) :}

[ 1 ] 刘炎序, 彭建, 汪安, 谢助, 韩忆楠. 生态系统健康研究进展. 生态学报, 2015, 35(18): 5920-5930.

[ 2 ] 姜萍, 姜秋月. “One Health”理念的提出及其当代价值. 自然辩证法通讯, 2018, 40(6) : 17-22.

[ 3 ] 孙燕, 周杨明, 张秋文, 易善桢. 生态系统健康: 理论/概念与评价方法. 地球科学进展, 2011, 26(8) : 887-896.

[ 4 ] 彭建, 吕丹娜, 董建权, 刘炎序, 刘前媛, 李冰. 过程耦合与空间集成: 国土空间生态修复的景观生态学认知. 自然资源学报, 2020, 35 (1) : 3-13.

[ 5 ] Costanza R, Norton B G, Haskell B D. Ecosystem Health: New Goals for Environmental Management. Washington: Island Press, 1992.

[ 6 ] Patil G P, Brooks R P, Myers W L, Rapport D J, Taillie C. Ecosystem health and its measurement at landscape scale: Toward the next generation of quantitative assessments. Ecosystem Health, 2001, 7(4) : 307-316.

[ 7 ] Rapport D J, Costanza R, McMichael A J. Assessing ecosystem health. Trends in Ecology \& Evolution, 1998, 13(10): $397-402$.

[ 8 ] Zhao C, Shao N, Yang S, Ren H, Ge Y, Zhang Z, Zhao Y, Yin X. Integrated assessment of ecosystem health using multiple indicator species. Ecological Engineering, 2019, 130: 157-168.

[ 9 ] Berrios F, Campbell D E, Ortiz M. Emergy-based indicators for evaluating ecosystem health: a case study of three benthic ecosystem networks influenced by coastal upwelling in northern Chile (SE Pacific coast). Ecological Indicators, 2018, 95: 379-393.

[10] Sun B D, Tang J C, Yu D H, Song Z W, Wang P G. Ecosystem health assessment: a PSR analysis combining AHP and FCE methods for Jiaozhou Bay, China. Ocean \& Coastal Management, 2019, 168: 41-50.

[11] Peng J, Liu Y X, Wu J S, Lv H L, Hu X X. Linking ecosystem services and landscape patterns to assess urban ecosystem health: A case study in Shenzhen City, China. Landscape and Urban Planning, 2015, 143: 56-68.

[12] 彭建, 王仰麟, 吴健生, 张玉清. 区域生态系统健康评价一一研究方法与进展. 生态学报, 2007, 27(11): 4877-4885.

[13] 赵文武, 刘月, 冯强, 王亚萍, 杨思琪. 人地系统耦合框架下的生态系统服务. 地理科学进展, 2018, 37(1): 139-151.

[14] 刘炎序, 徐光, 姜洪源, 胡晓旭, 彭建, 宋治清, 王仰麟. 东北林区生态系统服务与健康协同分析. 地理科学进展, 2015, 34 (6): 761-771.

[15] Rapport D J, Maffi L. Eco-cultural health, global health, and sustainability. Ecological Research, 2011, 26(6): 1039-1049.

[16] 畉天昳, 彭建, 刘炎序, 杨昒, 陈听. 基于集对分析的区域生态文化健康评价一以云南省大理白族自治州为例. 地理科学进展, 2017, $36(10): 1270-1280$.

[17］戴尔阜, 王亚慧. 横断山区产水服务空间异质性及归因分析. 地理学报, 2020, 75(3)：607-619.

[18] Su M R, Xie H, Yue W C, Zhang L X, Yang Z F, Chen S H. Urban ecosystem health evaluation for typical Chinese cities along the Belt and Road. Ecological Indicators, 2019, 101: 572-582.

[19] 孙然好, 魏琳沅, 张海萍, 陈利顶. 河流生态系统健康研究现状与展望一一基于文献计量研究. 生态学报, 2020, 40(10): 3526-3536.

[20] 陈万旭. 长江中游城市群生态系统健康时空演变及其城镇化驱动机制研究 [D]. 武汉: 中国地质大学, 2019.

[21] Peng J, Yang Y, Liu Y X, Hu Y N, Du Y Y, Meersmans J, Qiu S J. Linking ecosystem services and circuit theory to identify ecological security patterns. Science of the Total Environment, 2018, 644: 781-790. 
[22] Pan Z Z, He J H, Liu D F, Wang J W. Predicting the joint effects of future climate and land use change on ecosystem health in the Middle Reaches of the Yangtze River Economic Belt, China. Applied Geography, 2020, 124: 102293.

[23] 欧维新, 张伦嘉, 陶宇, 郭杰. 基于土地利用变化的长三角生态系统健康时空动态研究. 中国人口 - 资源与环境, 2018, 28( 5): 84-92.

[24] Sun X, Crittenden J C, Li F, Lu Z M, Dou X L. Urban expansion simulation and the spatio-temporal changes of ecosystem services, a case study in Atlanta Metropolitan area, USA. Science of the Total Environment, 2018, 622-623: 974-987.

[25] Chen W X, Ye X Y, Li J F, Fan X, Liu Q S, Dong W C. Analyzing requisition-compensation balance of farmland policy in China through telecoupling: a case study in the middle reaches of Yangtze River Urban Agglomerations. Land Use Policy, 2019, 83: 134-146.

[26] Sharp R, Tallis H T, Ricketts T, Guerry A D, Wood, S. A, Chaplin-Kramer R, Nelson E, Ennaanay D, Wolny S, Olwero N, Vigerstol K, Pennington D, Mendoza G, Aukema J, Foster J, Forrest J, Cameron D, Arkema K, Lonsdorf E, Kennedy C, Verutes G, Kim C K, Guannel G, Papenfus M, Toft J, Marsik M, Bernhardt J, Griffin R, Glowinski K, Chaumont N, Perelman A, Lacayo M, Mandle L, Hamel P, Vogl A L, Rogers L, Bierbower W, Denu D, Douglass J. 2016. InVEST + VERSION + User's Guide. The Natural Capital Project, Stanford University, University of Minnesota, The Nature Conservancy, and World Wildlife Fund.

[27] Wischmeier W H, Smith D. Predicting Rainfall Erosion Losses: A Guide to Conservation Planning. Washington: Department of Agriculture, 1978.

[28] Ouyang Z Y, Zheng H, Xiao Y, Polasky S, Liu J, Xu W H, Wang Q, Zhang L, Xiao Y, Rao E M, Jiang L, Lu F, Wang X K, Yang G B, Gong S H, Wu B F, Zeng Y, Yang W, Daily G C. Improvements in ecosystem services from investments in natural capital. Science, 2016, 352(6292) : 1455-1459.

[29] Chen W X, Chi G Q, Li J F. The spatial aspect of ecosystem services balance and its determinants. Land Use Policy, 2020 , 90 : 104263.

[30] Meng L R, Huang J, Dong J H. Assessment of rural ecosystem health and type classification in Jiangsu province, China. Science of the Total Environment, 2018, 615: 1218-1228.

[31] Peng J, Liu Y X, Li T Y, Wu J S. Regional ecosystem health response to rural land use change: a case study in Lijiang City, China. Ecological Indicators, 2017, $72:$ 399-410.

[32] Zheng W W, Ke X L, Zhou T, Yang B H. Trade-offs between cropland quality and ecosystem services of marginal compensated cropland - A case study in Wuhan, China. Ecological Indicators, 2019, 105: 613-620.

[33] 陈万旭, 李江风, 曾杰, 由端, 杨斌. 中国土地利用变化生态环境效应的空间分异性与形成机理. 地理研究, 2019, 38(9): $2173-2187$.

[34] 苏美蓉, 杨志峰, 陈涁. 基于生命力指数与集对分析的城市生态系统健康评价. 中国人口 - 资源与环境, 2010, 20(2) : 122-128.

[35] 刘培德, 滕飞. 基于混合指标值 TODIM 方法的东营市生态系统健康评价. 中国人口 - 资源与环境, 2017, 27(8)：167-176. 